\title{
Recycling assessment of multilayer flexible packaging films using design of experiments
}

\author{
Gabriel Abreu Uehara ${ }^{1 \star}$, Marcos Pini Françą and Sebastiao Vicente Canevarolo Junior ${ }^{1}$ \\ ${ }^{1}$ Departamento de Engenharia de Materiais, Universidade Federal de São Carlos - UFSCar, \\ São Carlos, SP, Brazil \\ ${ }^{2}$ Dow Brasil S.A., São Paulo, SP, Brazil \\ *gabrieluehara@live.com
}

\begin{abstract}
The viability of recycling post-industrial packaging waste, compounded from multilayer laminated PET-PE films, for production of polymer blends with good physico-mechanical performance is analyzed. Initially, several PET-PE model-blends were prepared from fresh polymers and were compounded with different formulations, based on design of experiments (DOE). Polymer compatibilizers based on maleic anhydride (PE-g-MA) and glycidyl methacrylate (E-GMA) have been used to promote the compatibilization reaction. The physico-mechanical properties of the model-blends were evaluated by response surface methodology (RSM). Finally, the post-industrial waste was compounded with the same concentration of compatibilizers in the previous set of model-blends. The DOE methodology showed to be a useful tool for assessing the recycling, since it helped to produce recycled materials with acceptable physico-mechanical properties. Between both compatibilizers studied, PE-g-MA showed to be the best additive for compatibilization due to the presence of a polyamide component in the waste, which undergoes a kinetically favorable compatibilization reaction.
\end{abstract}

Keywords: DOE, multilayer flexible packaging films, polymer blends, recycling, response surface methodology.

\section{Introduction}

Plastics are versatile materials that are present in all aspects of the modern life, providing goods and services that no other material would be able to provide. However, the accumulation of plastics in the environment has become a significant problem ${ }^{[1]}$. An ideal solution would be the recovery and the recycling of those materials, prolonging its life cycle and reducing environmental issues. Moreover, the majority of plastics still are based on oil feedstock, a non-renewable source of raw materials. Hence, recycling of post-industrial and post-consumer plastics has been spread rapidly among the industry ${ }^{[2]}$.

In most underdeveloped and emerging countries, socio-economic issues and the low aggregated value of the recycled materials lead to a poor recyclability index. The low aggregated value is caused by the low quality of the recycled materials available on the market, which prevents its use in applications with strict specifications. The recycled materials are generally compounded from a mixture of incompatible polymers ${ }^{[3]}$. This often results in products with lower quality and with variable consistency. Paradoxically, flexible packaging have increasingly been designed with multilayer films based on immiscible materials (PE, PET, nylon) in order to reach products with an adequate performance with an acceptable cost. This implies the production of great amounts of multilayer film waste with functional materials but with low capacity of reuse, leading to a holdback for the companies that have to face tougher environmental laws. One typical example is the Brazilian National Solid Waste Policy (NSWP), a new law implemented in 2010 which the main goal is to decrease the total volume of solid waste produced nationally. The NSWP establishes principles, objectives, guidelines, goals and actions in order to provide a better management of the several types of solid waste, increasing sustainability from the local level to the national level. This shall contribute even more for the utilization of recycled polymers, such as thermoplastics, but still represents a great challenge due to the low capacity of reuse of multilayer films as mentioned before.

With the objective to collaborate with the resolution of this dilemma, several studies on recycling methods have been proposed $^{[2-4]}$. Previous works have already shown that the use of polymer compatibilizers like polyethylene grafted with maleic anhydride ${ }^{[5,6]}$ or glycidyl methacrylate ${ }^{[6,7]}$ can enhance significantly the physico-mechanical properties of PET/PE blends. However, the great majority of these studies have been developed in a very limited way, considering the use of PET that was originated from different applications ${ }^{[8]}$ rather than flexible packaging, and also utilizing compatibilizers with an unknown composition ${ }^{[9]}$. As discussed, multilayer flexible packaging can be made with a gamma of different polymers with different physico-chemical properties, particularly polarity. Hence, compatibilization methods ${ }^{[10]}$ shall be developed in order to improve the adhesion between the components, enhancing the final properties for recycled materials. Moreover, there is a lack of literature regarding a complete scanning of the composition range on the properties of PET/PE systems based on multilayer packaging films. These needs take us to the main objective of this paper which was to build up PET/PE model blends, two of the main common polymers applied in the flexible packaging industry, in order to improve the performance of recycled scraps of multilayer packaging films. Thereby, these 
models can be used to provide tailored properties based on a physico-mechanical screening of PET/PE blends, using design of experiments (DOE) and multivariate data analysis.

\section{Materials and Methods}

\subsection{Materials}

The resins used for compounding the PET/PE model blends were a commercial virgin LLDPE (hereinafter denominated "PE") trade name Dowlex TM 2050B, supplied by Dow Brasil S.A. and Polyethylene Terephthalate (PET) grade Cleartuf Turbo ${ }^{\mathrm{TM}}$, supplied by M\&G Polímeros. Two different types of commercial compatibilizers were used: a random copolymer of ethylene-glycidyl methacrylate (E-GMA), trade name Lotader ${ }^{\mathrm{TM}}$ AX8840, supplied by Arkema and a copolymer of ethylene- $\alpha$-olefin grafted with maleic anhydride (PE-g-MA), trade name Amplify ${ }^{\mathrm{TM}}$ GR216, supplied by Dow Brasil S.A. The multilayer PET/PE films are commercial scraps of stand-up pouches, sent directly by the cosmetic industry, free of contamination and in the form of cut films.

\subsection{Melt processing}

For the model blends, PET pellets were carefully dried before use in a vacuum oven at $160^{\circ} \mathrm{C}$ during $5 \mathrm{~h}$. Adequate quantities of the components were weighted and the melt blended formulations were processed in a Werner \& Pfleiderer ZSK30 co-rotating twin-screw extruder. The temperature profile, kept constant throughout the experiments was 240-260-260-260-260-210 ${ }^{\circ} \mathrm{C}$. The melt strands were cooled down, pelletized, and kept for at least $24 \mathrm{~h}$ resting at room temperature, in sealed plastic bags before the injection molding of specimens.

\subsection{Design of experiments (DOE) and reprocessing of multilayer waste films}

The compatibilization study and the subsequent analysis of physico-mechanical behavior were made considering statistical tools by means of a $2^{2}$ full factorial central point DOE. The factors analyzed were (a) the concentration of the compatibilizers (E-GMA and PE-g-MA) and (b) the $\mathrm{PET} / \mathrm{PE}$ weight ratio. Table 1 illustrates the first DOE chosen.

In order to improve the sensibility of the model, the $2^{2}$ full factorial DOE was expanded to a central composite design, which further provides a screen of the physico-mechanical behavior by means of the response surface methodology (RSM). The expansion is shown in Figure 1, which compares both DOE. Figure 1b shows the four additional points (experiments) obtained by rotating the initial planning by a factor of, defined as " $\alpha$ rotability parameter" ${ }^{\text {"[11] }}$.

Table 2 illustrates the additional points in the design of experiments, after this expansion.

The last four runs (i.e., extrusion 8 to 11) are the edges of the rotated square in Figure 1, creating a star-like design. Since two compatibilizers were used, a total of $(11$ extrusions $) \times(2$ additives $)=22$ runs of compatibilized blends were needed. Additionally, 3 uncompatibilized blends with ratios of 25/75, 50/50 and 75/25 were also processed for comparison and assessment of the compatibilizer's performance. The pristine polymers (PE and PET) were also processed in the same way, totalizing 27 runs.

Models of PET/PE physico-mechanical properties were constructed using Statistica 7 software. A practical test was performed utilizing those models in order to evaluate the viability of recycling the waste of multilayer flexible packaging films. The multilayer waste films were shredded in smaller pieces in a laboratory knives mill (brand Primotécnica), dried in a vacuum oven at $80^{\circ} \mathrm{C}$ during $5 \mathrm{~h}$ to avoid hydrolysis of PET component during the reprocessing. The shredded multilayer waste was fed into the Werner \& Pfleiderer ZSK30 extruder by means of a K-tron gravimetric feeder to be melt blended with the compatibilizers, keeping all the previous processing conditions constant. The content of each compatibilizer was varied widely $(0,3,5,10$ and 15 weight $\%$ (hereinafter just w\%)). The melt strands of the compatibilized waste was cooled down, pelletized, and kept at least $24 \mathrm{~h}$ resting at room temperature, in sealed plastic bags before injection molding.

\subsection{Mechanical analysis}

The tensile test was done at room temperature in an Instron universal test machine, model 5569, according to ASTM D-638, at a constant pulling rate of $50 \mathrm{~mm} / \mathrm{min}$. The Izod impact test was done at room temperatures in a Ceast pendulum type machine (hammer of 4J), model 6545, following the standard ASTM D-256. The specimens were previously notched according to the same standard, kept in a room with controlled humidity and temperature at least $24 \mathrm{~h}$ before the test was carried out.

\subsection{Thermal characterization of the post-industrial scraps}

Thermal curves of the post-industrial multilayer waste was taken in a differential scanning calorimeter, DSC-Q2000 from TA Instrument, tested in a nitrogen atmosphere of

Table 1. Design of experiments: $2^{2}$ full factorial with central point.

\begin{tabular}{|c|c|c|c|c|}
\hline \multirow{2}{*}{$\begin{array}{c}\text { Experiment } \\
\text { Extrusion }\end{array}$} & \multicolumn{2}{|c|}{ Codification } & \multicolumn{2}{|c|}{ Variables } \\
\hline & PET/PE & Compatibilizer & PET/PE (wt\%) & Compatib. (wt\%) \\
\hline 1 & -1 & -1 & $25 / 75$ & 5 \\
\hline 2 & +1 & -1 & $75 / 25$ & 5 \\
\hline 3 & -1 & +1 & $25 / 75$ & 15 \\
\hline 4 & +1 & +1 & $75 / 25$ & 15 \\
\hline 5 & 0 & 0 & $50 / 50$ & 10 \\
\hline 6 & 0 & 0 & $50 / 50$ & 10 \\
\hline 7 & 0 & 0 & $50 / 50$ & 10 \\
\hline
\end{tabular}




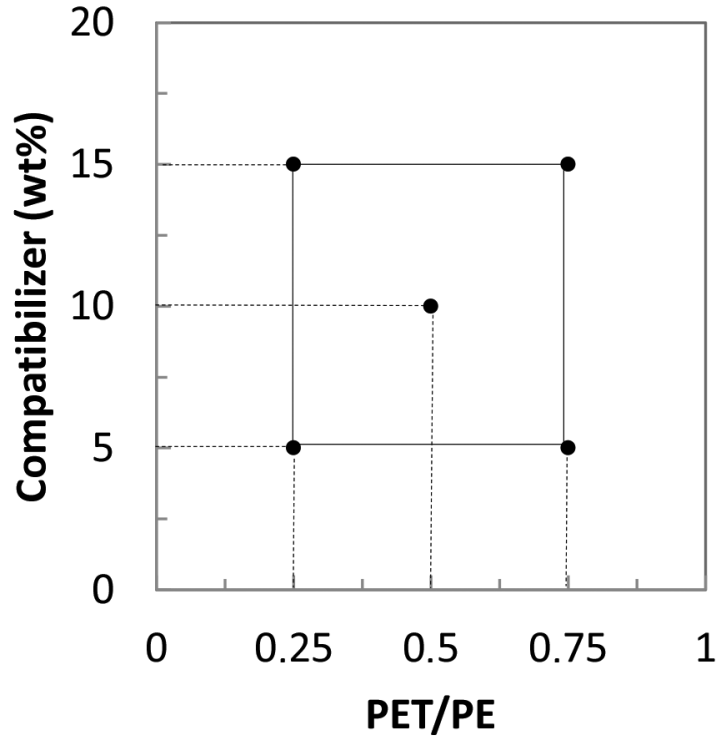

(a)

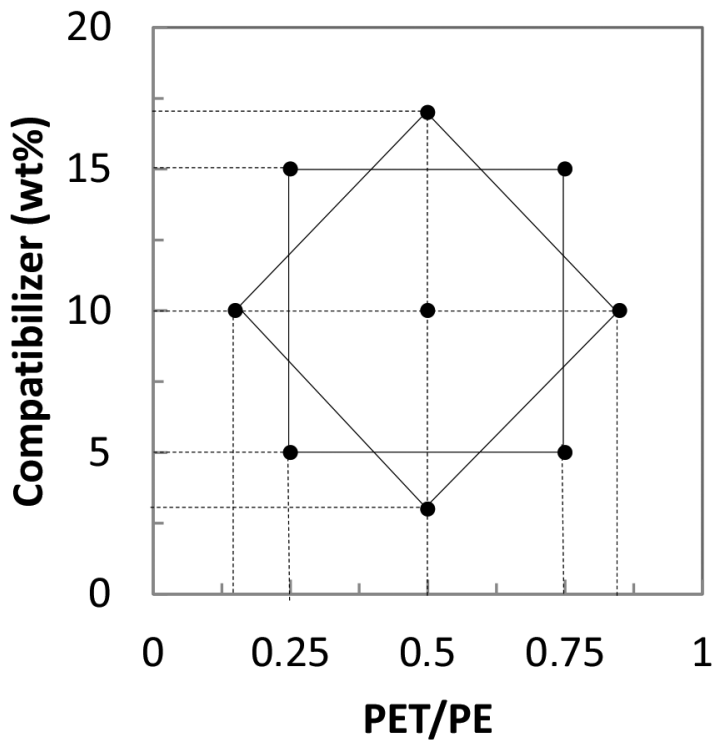

(b)

Figure 1. Diagram of the (a) $2^{2}$ full factorial design with central point and its rotation to get (b) a central composite design.

Table 2. Design of experiments: central composite (star-like design).

\begin{tabular}{ccccc}
\hline Experiment & \multicolumn{2}{c}{ Codification } & \multicolumn{2}{c}{ Variables } \\
\hline Extrusion No. & PET/PE & Compatibilizer & PET/PE (wt\%) & Compatib. (wt\%) \\
\hline 1 & -1 & -1 & $25 / 75$ & 5 \\
2 & +1 & -1 & $75 / 25$ & 5 \\
3 & -1 & +1 & $25 / 75$ & 15 \\
4 & +1 & +1 & $75 / 25$ & 15 \\
5 & 0 & 0 & $50 / 50$ & 10 \\
6 & 0 & 0 & $50 / 50$ & 10 \\
7 & 0 & 0 & $50 / 50$ & 10 \\
8 & $-\sqrt{2}$ & 0 & $15 / 85$ & 10 \\
9 & $+\sqrt{2}$ & 0 & $85 / 15$ & 10 \\
10 & 0 & $-\sqrt{2}$ & $50 / 50$ & 3 \\
11 & 0 & $+\sqrt{2}$ & $50 / 50$ & 17
\end{tabular}

$50 \mathrm{~mL} / \mathrm{min}$, at a heating rate of $10{ }^{\circ} \mathrm{C} / \mathrm{min}$ up to $280{ }^{\circ} \mathrm{C}$, held for 5 minutes and cooled at the same heating rate until $30{ }^{\circ} \mathrm{C}$. A total of seven DSC runs regarding random samples collected from the waste sent by the manufacturer was performed. In order to obtain an approximate value of the scraps composition, a PET/PE calibration curve was made with some of the blends composition that was previously extruded. The chosen compositions for fitting the calibration curve were: pristine PET, pristine PE, and three uncompatibilized blends thereof $(25 / 75,50 / 50$ and $75 / 25)$.

\section{Results and Discussions}

\subsection{Mechanical behavior of uncompatibilized PET/PE blends}

Figure 2 shows the mechanical behavior of uncompatibilized blends during tensile testing. In general, immiscible blends show a two phase morphology, which consists of a continuous matrix and a droplet-like dispersed phase ${ }^{[12,13]}$. This is most often when the blend composition is beyond the phase inversion region. The final morphology is dependent on several parameters such as: processing conditions, $\mathrm{PET} / \mathrm{PE}$ ratio, temperature of crystallization of the individual components and the viscosity ratio. Additionally, the components may crystallize at different times and in different manners, leading to different morphologies and hence different properties ${ }^{[10]}$.

As seen in Figure 2a, the addition of PE decreases the yield strength of the blend. This can be explained by the fact that PET is tougher than PE with much higher yield strength. Therefore, the addition of a soft polyolefin dispersed phase into a matrix of the rigid polyester reduces the volumetric presence of the PET in the transversal section of the specimen, decreasing yield strength value of the blend. When PE builds up the matrix, the addition of rigid particles of PET tends to slowly enhance the yield strength behavior of the blend. These results are related with the model of two-phase systems proposed by Uemura and Takayanagi ${ }^{[14]}$. A secondary effect is the reduction of the crystallization rate and the 


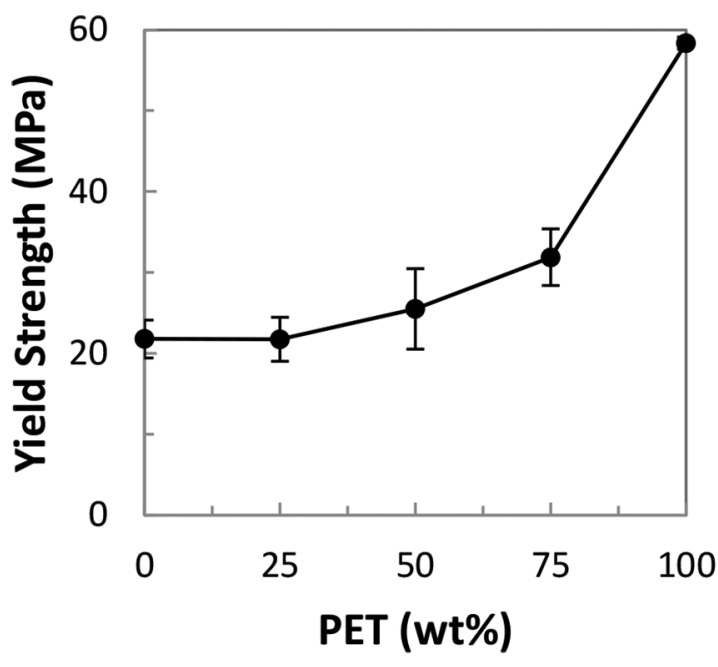

(a)

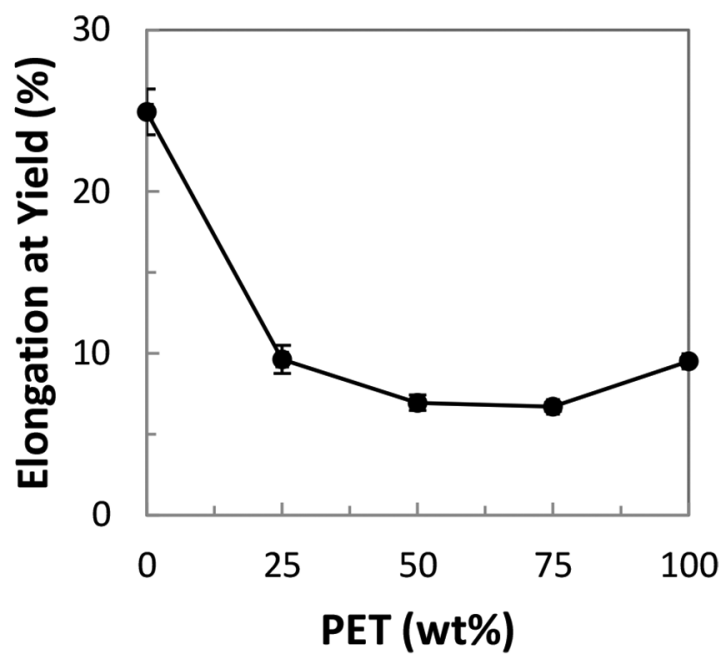

(b)

Figure 2. (a) Yield Strength and (b) Elongation at Yield of uncompatibilized PET/PE blends as a function of the blend's composition.

degree of crystallinity of PET by blending. This is likely due to the expense of energy required by the crystallizing growth front to reject and deform the polyolefin dispersed molten droplets, which can cause a marked depression of the spherulite growth rate ${ }^{[15]}$. Figure $2 \mathrm{~b}$ shows a deleterious effect (minimum point) of the blending in the elongation at yield of the blend which is in good agreement with the results obtained by Boutevin et al. ${ }^{[7]}$.

Figure 3 shows the Izod impact strength of the pristine polymers, PE and PET, and the uncompatibilized blends. There is a deleterious effect when both polymers are blended without compatibilizers, including some compositions which show their impact strength lower than the individual components. In fact, there is a minimum value around PET/PE 50/50 composition, which is likely due to the formation of a co-continuous phase which both components form the matrix phase.

Blending is a process often used to provide tailored product properties for a specific application. However, this situation is more complex when applied to immiscible polymers, since the desired properties are not achieved readily. One possible solution is the use of compatibilizers. Theses additives are responsible for enhancing the phase dispersion and stability, in the same way they improve the adhesion between the phases ${ }^{[16]}$. Compatibilizers also affect both phase morphology and the crystallization behavior of the blend's components. Therefore, since these factors are closely related to the final properties of the product, it is worth to study the effects of compatibilizers onto physico-mechanical behavior of the blends.

\subsection{Mechanical behavior of compatibilized PET/PE blends with PE-g-MA}

Figure 4 shows the yield strength predicted means of PET/PE blends compatibilized with PE-g-MA. Overall, the yield strength is predicted to increase with the increase of the PET phase. According to Table 3, the effect due to the PET content (\%PET) is approximately 7.4. This means that

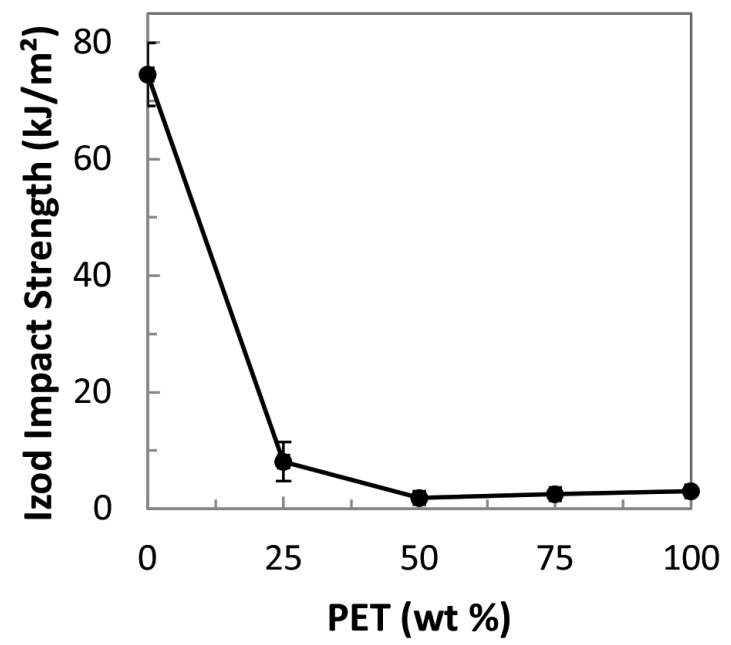

Figure 3. Izod impact strength of PET/PE blends as a function of the blend's composition.

when the PET content climbs from 25 to $75 \mathrm{w} \%$, the yield strength increases by 7.4 MPa on average. Similarly, also according to Table 3 , when the compatibilizer concentration is increased from 5 to $15 \mathrm{w} \%$, there is a $2.2 \mathrm{MPa}$ reduction of yield strength on average.

Figure 5 shows the Pareto chart for the Young modulus, E. The variable $\%$ PE-g-MA had an effect of -0.16 , meaning that if the content of PE-g-MA is increased from 5 to $15 \%$, the modulus of elasticity would decrease $0.16 \mathrm{GPa}$ on average. This is due to the fact that the compatibilizer has an elastomeric behavior which reduces the elastic modulus. Moreover, the anhydride groups of PE-g-MA can react with the PET hydroxyl end groups, promoting a chemical anchoring between the polyester and the compatibilizer as indicated by Figure $6^{[17]}$. Additionally, the polyolefin phase of PE-g-MA is miscible with the PE component, forming a physical anchoring. 
Table 3. Simulated effects (principal and 2-order) of the Yield Strength of PET/PE blends compatibilized with PE-g-MA.

\begin{tabular}{cccccccccc}
\hline \multirow{2}{*}{ Extrusion No. } & \multicolumn{2}{c}{ Codified } & \multicolumn{3}{c}{ Real } & \multicolumn{2}{c}{ Answer } & \multicolumn{3}{c}{ Effects } \\
\cline { 2 - 11 } & $\begin{array}{c}\text { PET/PE } \\
\text { Ratio }\end{array}$ & Comp. & $\begin{array}{c}\text { PET/PE } \\
\text { Ratio }\end{array}$ & \% Comp. & $\begin{array}{c}\text { Yield Strength } \\
\text { (MPa) }\end{array}$ & $\mathbf{1}$ & $\mathbf{2}$ & $\mathbf{1 2}$ \\
\hline 1 & -1 & -1 & 25 & 5 & 22.0 & -22.0 & -22.0 & 22.0 \\
2 & 1 & -1 & 75 & 5 & 33.7 & 33.7 & -33.7 & -33.7 \\
3 & -1 & 1 & 25 & 15 & 24.1 & -24.1 & 24.1 & -24.1 \\
4 & 1 & 1 & 75 & 15 & 27.2 & 27.2 & 27.2 & 27.2 \\
5 & 0 & 0 & 50 & 10 & 24.2 & 0 & 0 & 0 \\
6 & 0 & 0 & 50 & 10 & 23.8 & 0 & 0 & 0 \\
7 & 0 & 0 & 50 & 10 & 25.4 & 0 & 0 & 0 \\
& & & & & & Simulated Effects & 7.4 & -2.2 & -4.3 \\
\hline
\end{tabular}

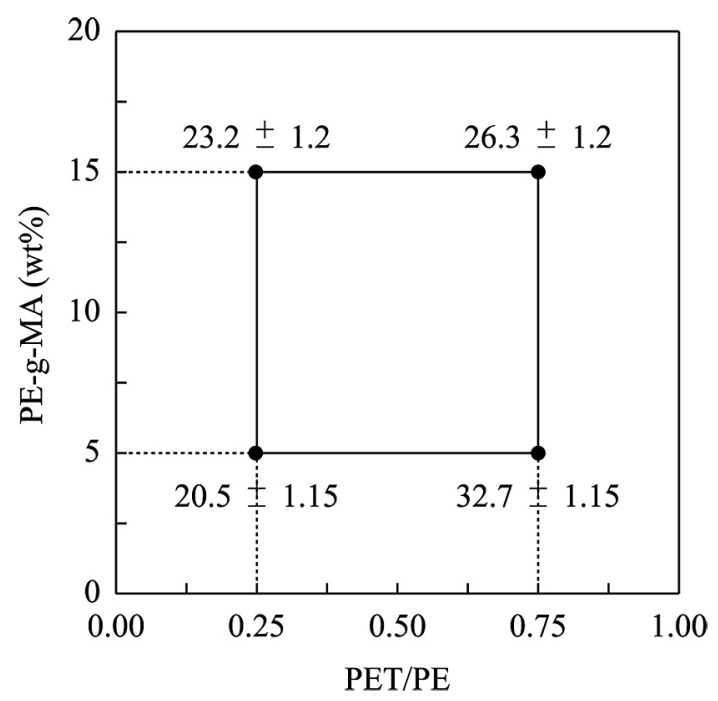

Figure 4. Predicted Means for Yield Strength (in MPa) with two factors at two levels. The model includes: main effects and 2-way interaction. Errors estimated based on a $95 \%$ confidence interval.

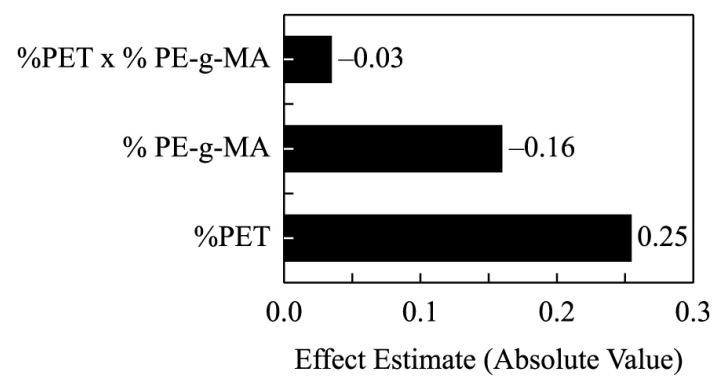

Figure 5. Pareto's Chart of Effects of Young Modulus (GPa) of $\mathrm{PET} / \mathrm{PE}$ blends compatibilized with PE-g-MA.<smiles>O=C(O)O</smiles>
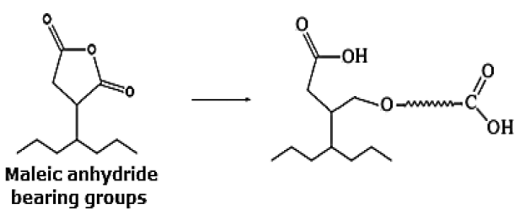

Figure 6. Chemical reaction between the hydroxyl end groups of the PET with the maleic anhydride groups of the PE-g-MA compatibilizer grafted copolymer.

\subsection{Mechanical behavior of compatibilized PET/PE blends with E-GMA random copolymer}

Figure 7 shows the average predicted Yield Strength for PET/PE blends compatibilized with E-GMA random copolymer. Overall, as in the previous case of PE-g-MA compatibilization, the Yield Strength is predicted to increase with the increase of the PET component, as also predicted by Table 4. Conversely, when the compatibilizer concentration is increased from 5 to $15 \mathrm{w} \%$, the Yield Strength increases approximately 7.3 $\mathrm{MPa}$ on average. This result is the opposite from that obtained when the PE-g-MA compatibilizer was used.

The Young modulus was also assessed using the Pareto's Chart shown in Figure 8. As expected, the increase of PET content increases the Young Modulus, E. On the other hand, the compatibilization using E-GMA random copolymer reduces the elastic modulus. However, this reduction when compared with the one produced by the PE-g-MA grafted copolymer is only half of the value. This is likely due to the different kind of structure that both compatibilizers have. PE-g-MA has an elastomeric behavior, reducing even more the values of Young modulus.

In terms of chemical reactivity, the epoxy group in E-GMA can undergo reactions with both reactive hydroxyl and carboxyl end groups of PET. The presence of a copolymer that has mutual affinity between the polyester and the polyolefin phase promotes the reduction of the size of second phase particles, increasing the adhesion between the two phases. However, the use of copolymers containing GMA groups always increases the viscosity ${ }^{[4]}$. This is attributed to the formation of crosslinking during the blending, as illustrated by Figure 9 .

The aforementioned reactions occur simultaneously, giving rise to complex macromolecular structures, impacting directly on mechanical properties of the blends compatibilized with E-GMA, as detailed in the further sections.

\subsection{Experimental expansion: tensile properties of PET/PE model blends}

Figure 10 shows the effect of PET/PE ratio and concentration of compatibilizers on the elongation at break of the blends. The blends compatibilized with PE-g-MA (Figure 10a) showed higher elongation at break mainly when both concentration of PE and compatibilizer were kept high. With E-GMA, this behavior was noticed regarding 
higher amounts of PET instead of PE. This is likely due to the possibility of chain extension arising from the reaction between PET end groups and GMA, which increase the probability of entanglements along PET macromolecules. As consequence, the macromolecules will offer more resistance to uncoil, enhancing then the elongation at break of the blend.

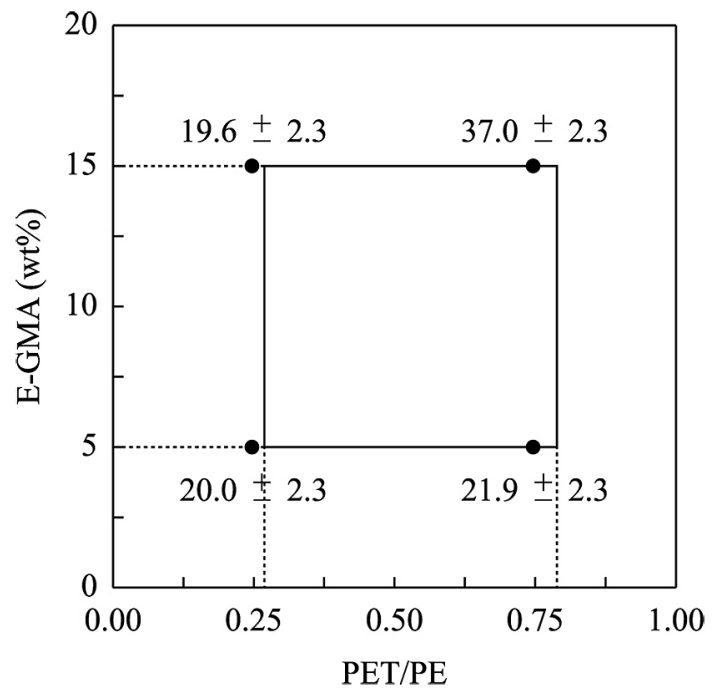

Figure 7. Predicted Means of Yield Strength (in MPa) with two factors at two levels. The model includes: main effects and 2-way interaction. Errors estimated based on a $95 \%$ confidence interval.

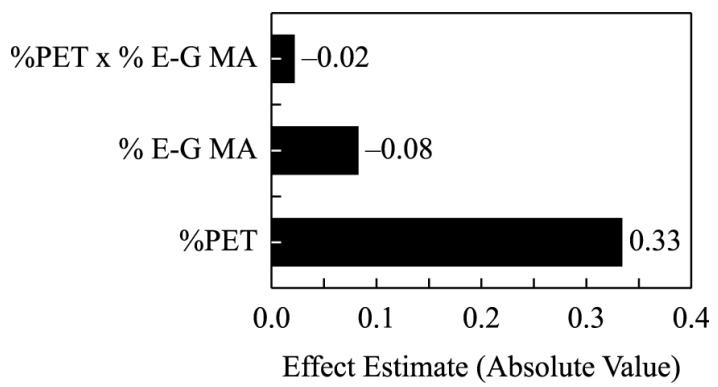

Figure 8. Pareto's chart of effects for Young modulus (GPa) of PET/PE blends compatibilized with E-GMA random copolymer.
As discussed before, the GMA reaction with both PET end groups had been reported extensively in the literature ${ }^{[6,18-20]}$. The PE-g-MA grafted copolymer has a much lower number of maleic anhydride groups per polyethylene chain, lowering the probability of chain extension in the case of blends compatibilized with PE-g-MA grafted copolymer. Instead, the $\alpha$-olefin phase of the compatibilizer establishes physical interaction with the PE phase, generating physical anchoring due to the miscibility between the components, explaining the higher elongations noticed when the PE was the matrix phase. Figure 11 shows that PE-g-MA is a better compatibilizer considering the elongation at yield behavior. E-GMA also developed a good response, particularly in the region of higher content of compatibilizer and high $\mathrm{PET} / \mathrm{PE}$ ratio.

\subsection{Experimental expansion: izod impact strength of PET/PE model blends}

Better impact properties could be achieved using low to medium amounts of compatibilizers. Figure 12 shows the effect of addition of 5 and 15w\% PE-g-MA and E-GMA onto the Izod impact strength of the blends, as function of the $\mathrm{PET} / \mathrm{PE}$ ratio.

In both PET/PE compositions, there's a clear tendency of enhancement of the impact properties when utilizing the compatibilizers. However, a more pronounced effect was evidenced at $25 / 75 \mathrm{w} \%$ PET/PE composition (Figure 12a), where the energies were shifted from $8.1 \mathrm{~kJ} / \mathrm{m}^{2}$ (uncompatibilized) to 60.4 and $83.1 \mathrm{~kJ} / \mathrm{m}^{2}$ for PE-g-MA and E-GMA, respectively. This represents an enhancement of $645 \%$ and $926 \%$ in the impact strength values (with respect to the uncompatibilized blends). This seems to be a paramount result, since it could be obtained regarding lower amounts of compatibilizers $(5 \mathrm{w} \%)$. Overall, higher amounts of the compatibilizers seem to increase even more the impact strength (Figure 12b). Surprisingly, the addition of $15 \mathrm{w} \%$ of PE-g-MA seems to produce compatibilized blends with equivalent performance than those blends compatibilized with $15 \mathrm{w} \%$ of E-GMA. This unexpected result is likely to be attributed to the higher reactive content of E-GMA, which has $8 \mathrm{w} \%$ of glycidyl groups, against approximately $1 \mathrm{w} \%$ of maleic anhydride in the case of PE-g-MA. The more concentrated the compatibilizer, the higher the chance of occurring parallel reactions, such as crosslinking, as previously indicated in Figure 9, which is detrimental from the physico-mechanical point of view.

Table 4. Simulated effects (principal and 2-order) of the Yield Strength for PET/PE blends compatibilized with E-GMA random copolymer.

\begin{tabular}{|c|c|c|c|c|c|c|c|c|}
\hline \multirow[b]{2}{*}{ Extrusion No. } & \multicolumn{2}{|c|}{ Codified } & \multicolumn{2}{|c|}{ Real } & \multirow{2}{*}{$\begin{array}{c}\text { Answer } \\
\text { Yield Strength } \\
\text { (MPa) } \\
\end{array}$} & \multicolumn{3}{|c|}{ Effects } \\
\hline & $\begin{array}{c}\mathrm{PET} / \mathrm{PE} \\
\text { Ratio }\end{array}$ & Comp. & $\begin{array}{c}\text { PET/PE } \\
\text { Ratio }\end{array}$ & $\begin{array}{c}\text { Comp. } \\
(\%)\end{array}$ & & 1 & 2 & 12 \\
\hline 1 & -1 & -1 & 25 & 5 & 22.0 & -22.0 & -22.0 & 22.0 \\
\hline 2 & 1 & -1 & 75 & 5 & 24.0 & 24.0 & -24.0 & -24.0 \\
\hline 3 & -1 & 1 & 25 & 15 & 21.7 & -21.7 & 21.7 & -21.7 \\
\hline 4 & 1 & 1 & 75 & 15 & 39.1 & 39.1 & 39.1 & 39.1 \\
\hline 5 & 0 & 0 & 50 & 10 & 21.4 & 0 & 0 & 0 \\
\hline 6 & 0 & 0 & 50 & 10 & 20.9 & 0 & 0 & 0 \\
\hline \multirow[t]{3}{*}{7} & 0 & 0 & 50 & 10 & 23.2 & 0 & 0 & 0 \\
\hline & & & & & Sum & 19.3 & 14.7 & 15.5 \\
\hline & & & & & Simulated Effects & 9.6 & 7.3 & 7.7 \\
\hline
\end{tabular}




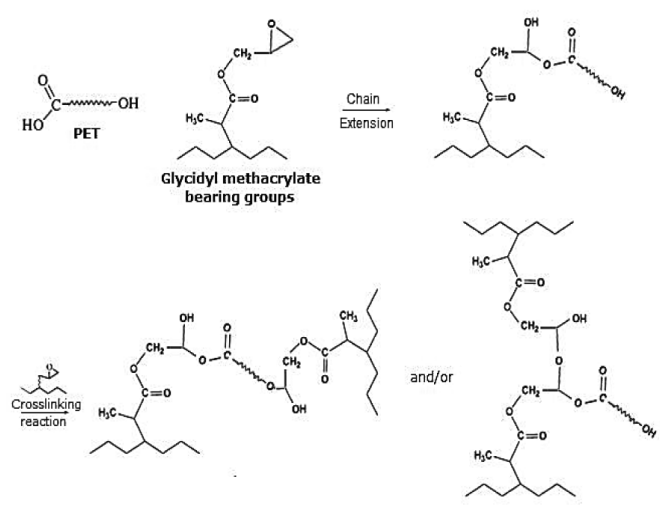

(a)
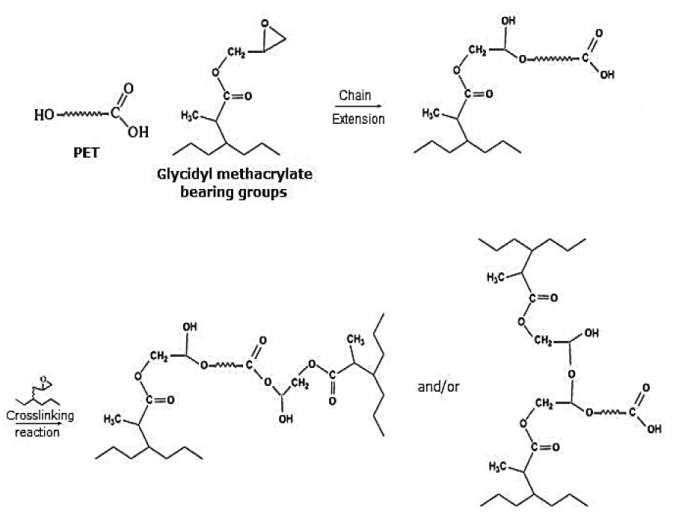

(b)

Figure 9. Chemical reaction between PET end groups with E-GMA and the subsequent formation of crosslinking. (a) Chain extension with $\mathrm{OH}$ end group and crosslinking (b) chain extension with $\mathrm{COOH}$ end group and crosslinking.

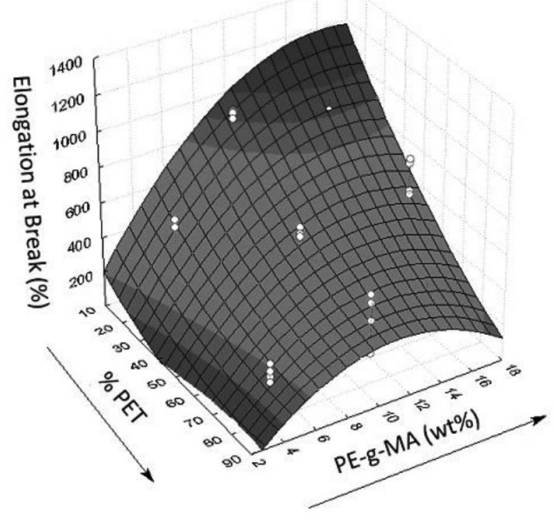

(a)

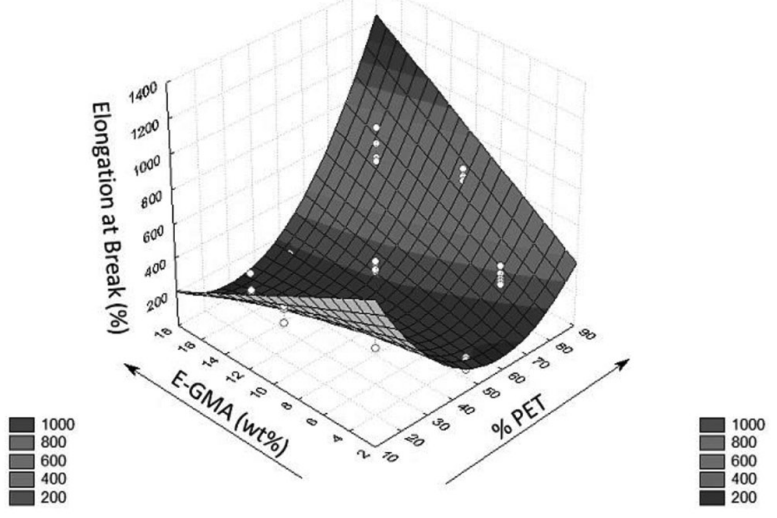

(b)

Figure 10. Response surfaces of Elongation at Break as a function of PET/PE ratio, type and concentration of compatibilizer. Blends with (a) PE-g-MA and (b) E-GMA.

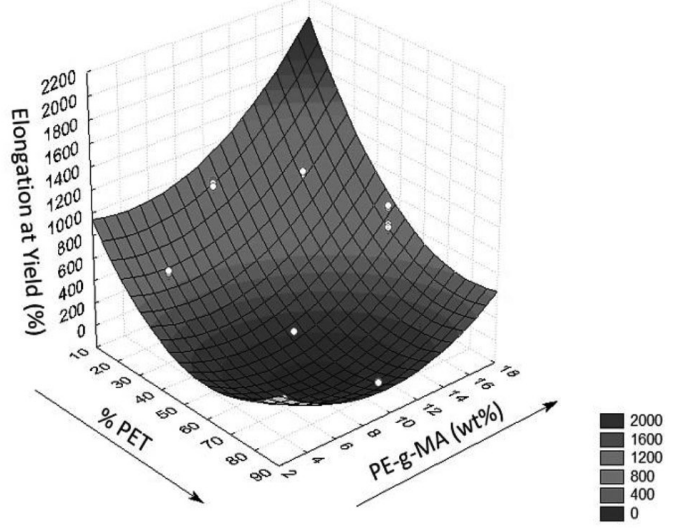

(a)

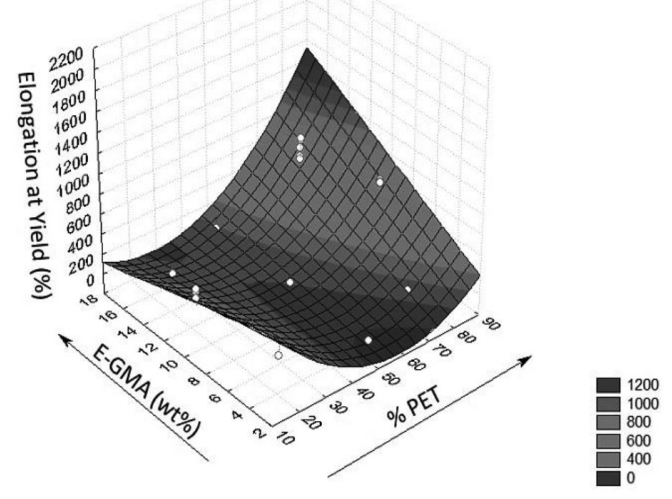

(b)

Figure 11. Response surfaces of Elongation at Yield as function of PET/PE ratio, type and concentration of compatibilizer. Blends with (a) PE-g-MA and (b) E-GMA. 
On the other hand, PE-g-MA cannot undergo crosslinking due to the reactivity of the anhydride (cyclic acid) ring, which will only react with the hydroxyl end groups of PET. In other words, the occurrence of parallel reactions as in the case of E-GMA might influence negatively the effectiveness of the compatibilization reaction when used in higher concentrations. This shall explain why E-GMA didn't have a superior performance than PE-g-MA when utilized at higher concentrations $(15 \mathrm{w} \%)$ at 25/75 $\mathrm{PET} / \mathrm{PE}$ composition.

Despite of being well represented with bar graphs, the values of impact strength could be better visualized utilizing RSM, which provides a multivariate data analysis. The regression coefficients for both models are shown in Equation 1 and 2, where corresponds the amount of PET (in w\%), corresponds to the concentration of compatibilizer (in w\%) and is the Izod impact strength (in $\mathrm{kJ} / \mathrm{m}^{2}$ ). The response surfaces of the models are also represented in Figure 13.

$$
\begin{aligned}
& z=-4.32 x+0.037 x^{2}-0.45 y+0.16 y^{2}- \\
& 0.055 x y+135.4 \\
& z=-5.08 x+0.038 x^{2}-4.48 y+0.27 y^{2}+186.2
\end{aligned}
$$

Overall, Figure 13 shows that both compatibilizers had similar surfaces. E-GMA seems to be slightly more effective at higher amounts of PET. On the other hand, at higher amounts of PE, both E-GMA and PE-g-MA seems to have similar behavior, especially for higher amounts of compatibilizers. Both surfaces exhibit a point of minimum somewhere around the co-continuous region (50/50). According to Equation 1 , the blends compatibilized with PE-g-MA are expected to have a minimum point in the region around PET/PE $65 / 35$ with $10 w \%$ of the compatibilizer. Similarly, Equation 2 foresees that a minimum point is expected somewhere around $70 / 30$ with $8 \mathrm{w} \%$ of E-GMA. The main conclusion is that both regions should be avoided, since it yields the lowest values of Izod impact strength.

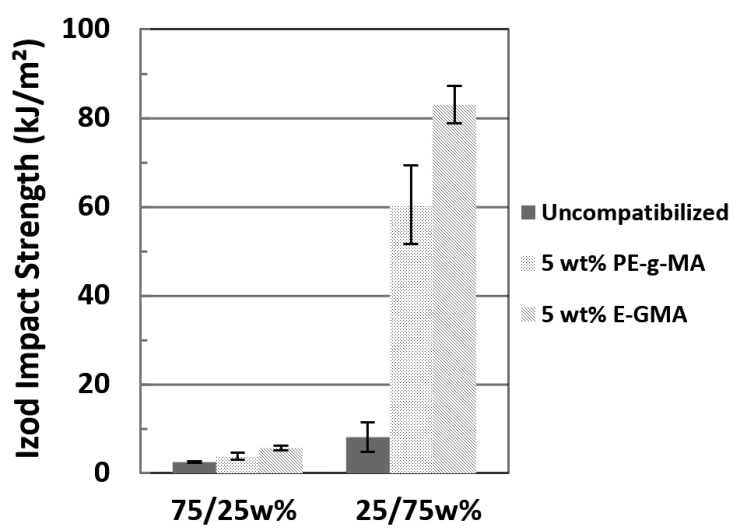

(a)

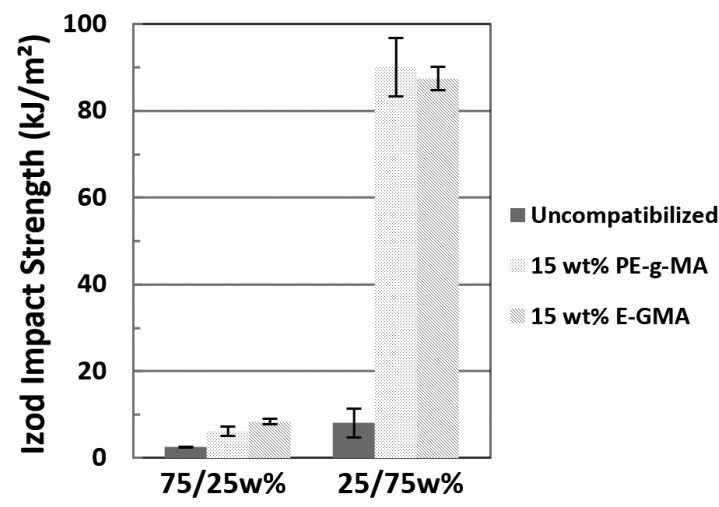

(b)

Figure 12. Izod impact strength of PET/PE blends (relative concentrations as shown) compatibilized with (a) $5 \mathrm{w} \%$ and (b) $15 \mathrm{w} \%$ of each compatibilizer. Uncompatibilized blend is also shown for comparison.

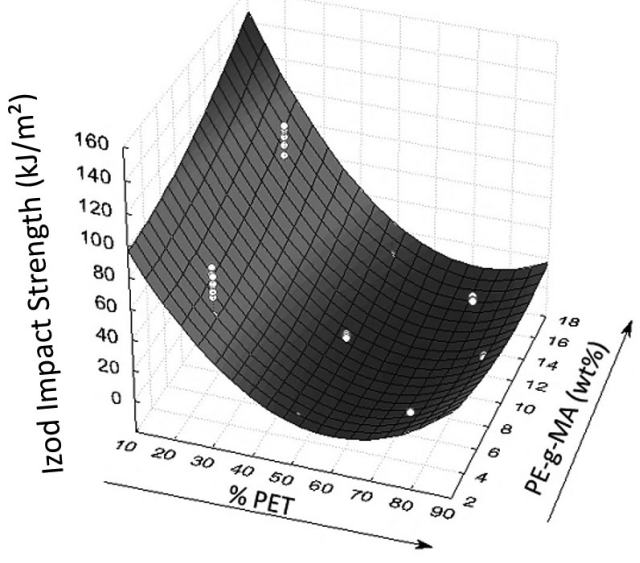

(a)

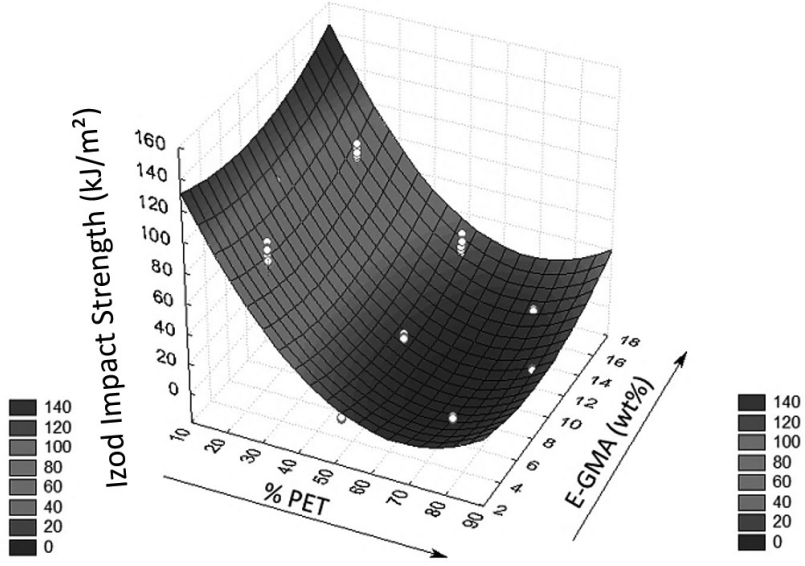

(b)

Figure 13. Response surfaces of Izod impact strength as function of PET/PE ratio and \% compatibilizer. (a) Blends compatibilized with PE-g-MA and (b) blends compatibilized with E-GMA. 


\subsection{Thermal characterization of the post-industrial multilayer flexible packaging films}

Figure 14 shows a thermal cycling of the multilayer scrap sample. The two characteristic peaks around $130^{\circ} \mathrm{C}$ and $250^{\circ} \mathrm{C}$ are attributed, respectively, to the fusion of PE and PET components. An endotherm peak around $110^{\circ} \mathrm{C}$ was also detected, which is attributed to the peak of fusion of the adhesives, commonly made of LDPE. Unexpectedly, an endotherm peak around $210^{\circ} \mathrm{C}$ was also detected, which is attributed to a minor content of a Nylon- 6 component that ought to be acting as a barrier material in the package.

Considering that the nylon present in the structure will play the same role as PET during the compatibilization reaction (i.e., both of them will react with the compatibilizers, although at different rates), it is possible to use the calibration curve that had been constructed to estimate the total "reactive" fraction (PET+Nylon) present in the structure. The calibration curve obtained was with $\mathrm{R}^{2}$ equal to 0,998 . Replacing the population mean value of 0.23 (i.e., the normalized value of $\left.\Delta \mathrm{H}_{\mathrm{PET}} /\left(\Delta \mathbf{H}_{\text {nylon }}+\Delta \mathbf{H}_{\mathrm{PET}}+\Delta \mathbf{H}_{\mathrm{PE}}\right)\right)$ led to a value equal to

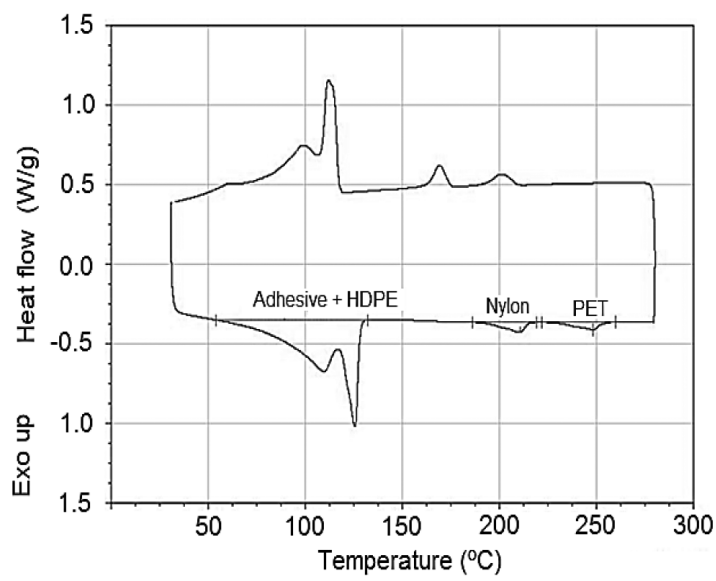

Figure 14. Thermal cycling of post-industrial multilayer flexible packaging film recorded in a DSC.
22.5 , meaning that the multilayer film contains approximately $22.5 \mathrm{w} \%$ of reactive content (PET+Nylon) and $77.5 \mathrm{w} \%$ of PE. According to the manufacturer, the real composition of the multilayer plastic films is of $70 \mathrm{w} \%$ of PE, $10 \mathrm{w} \%$ of PET, $10 \mathrm{w} \%$ of Nylon- 6 and the remainder is divided between adhesives and ink. Therefore, our estimation is quite similar to the real composition. Based on this, it was possible to estimate which PET/PE composition our model was situated before the reprocessing of the multilayer waste was done.

\subsection{Reprocessing of the post-industrial multilayer flexible packaging film waste: mechanical properties of the compatibilized scraps}

Figure 15 shows the behavior of the compatibilized scraps under tensile testing when the specimens reach the rupture.

The breaking strength tends to increase with the increase of PE-g-MA content, while remain almost constant for the scraps compatibilized with E-GMA. On the other hand, elongation at break increased significantly for the scraps compatibilized with PE-g-MA. The better performance of PE-g-MA is attributed to the presence of the nylon component in the multilayer film waste. As evidenced by Macosko et al. ${ }^{[16]}$, the amine terminal groups of nylon undergo a very fast reaction ( around $10^{3} \mathrm{~kg} / \mathrm{mol} . \mathrm{min}$ ) with the succinic rings of maleic anhydride. This reaction, that has also been reported by Hage and Pessan ${ }^{[2]}$, leads to imide formation. In contrast, the reaction between amines and epoxy rings of GMA could also occur, but at a very lower rate ( $\mathrm{kg} / \mathrm{mol} . \mathrm{min})$. In other words, the reaction between PE-g-MA and nylon occurs preferentially, rather than with E-GMA, meaning that PE-g-MA will firstly compatibilize the nylon component and subsequently the PET component. When the PE-g-MA content is low ( 3 or $5 \mathrm{w} \%$ ), the compatibilization reaction will take place preferentially with nylon, remaining PET component uncompatibilized, resulting in poor mechanical properties. On the other hand, higher amounts of PE-g-MA will compatibilize both nylon and PET components. This explains why Figure 15b gave rise to a sudden climb when switching from 5 to $10 \mathrm{w} \%$ of PE-g-MA.
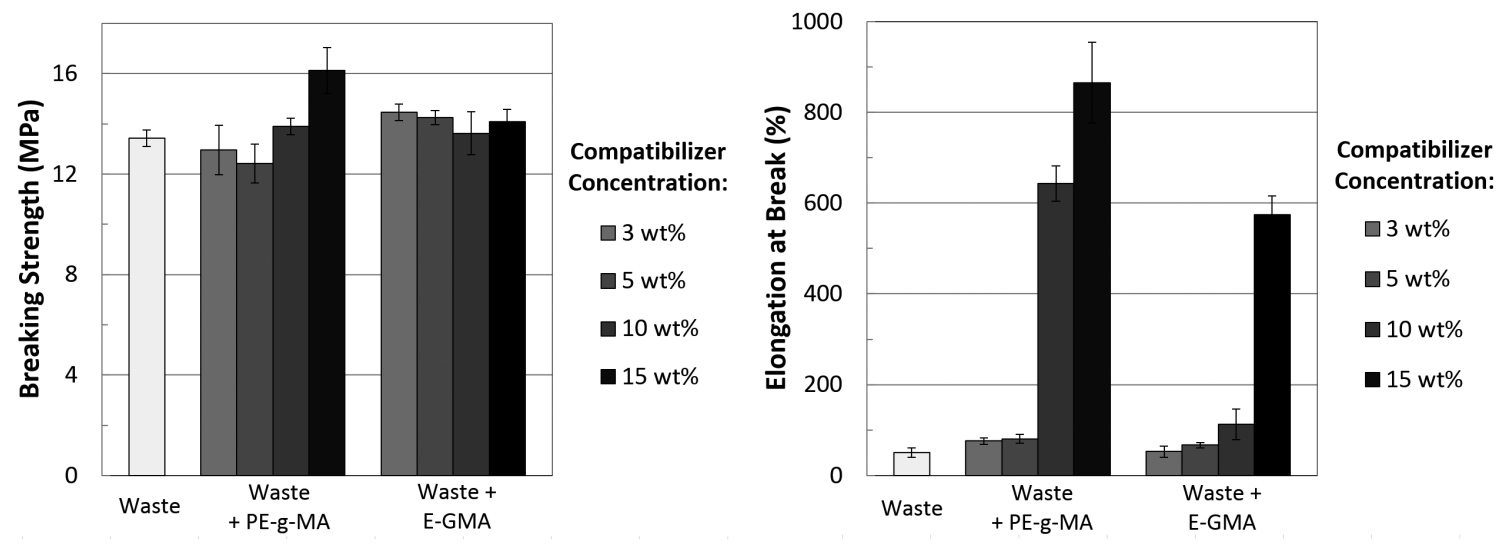

Figure 15. Physico-mechanical behavior for pure and compatibilized multilayer film waste. (a) Breaking strength and (b) Elongation at break. 


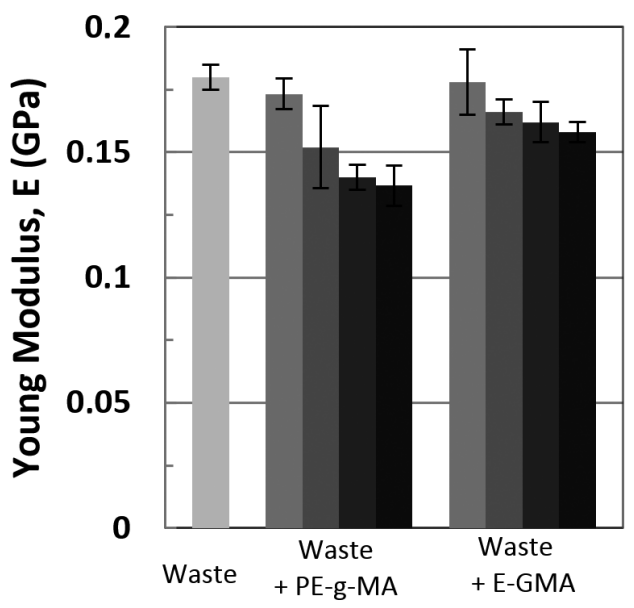

(a)

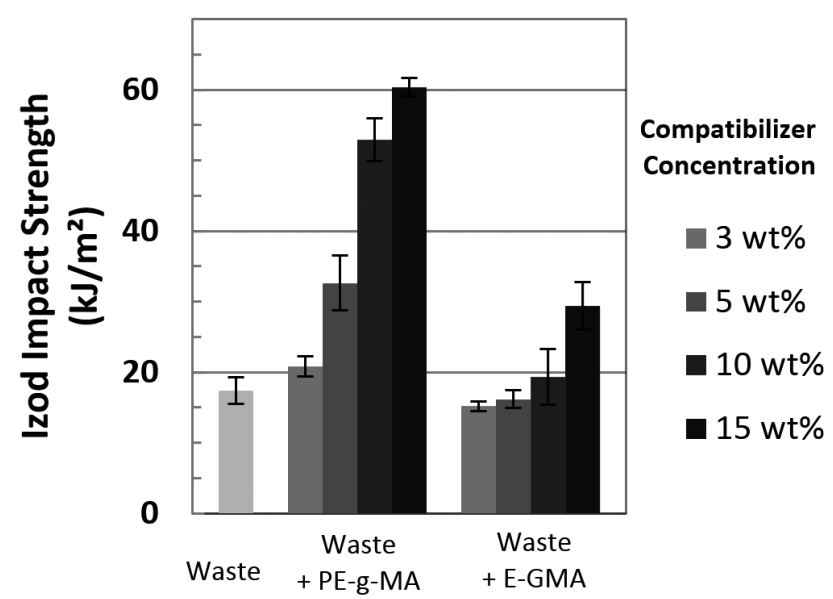

(b)

Figure 16. Physico-mechanical behavior for pure and compatibilized multilayer film waste. (a) Young Modulus, E and (b) Izod impact strength.

The same argument is valid for E-GMA, except that for this case the glycidyl groups are going to react preferentially with $\mathrm{COOH}$ end groups of PET ${ }^{[22]}$. If E-GMA is present in sufficient amounts, the competition of the reactions between nylon, GMA and PET end groups could be overcome. This behavior is also shown in Figure $15 \mathrm{~b}$ when the content of E-GMA is switched from lower to higher amounts. However, the crosslinking effect of GMA has to be taken into account, which is depreciative for mechanical properties, explaining why E-GMA didn't show equivalent performance than PE-g-MA.

Figure 16a shows the Young Modulus, E for the compatibilized scraps. Overall, the reduction of Young modulus seems to be slightly more pronounced for the scraps compatibilized with PE-g-MA. This result seems to be following good agreement with the Pareto chart analysis shown previously (Figure 5 and 8), where the model foresees that PE-g-MA was responsible for a superior decrease of Young modulus.

Figure 16b shows the results of Izod impact strength for the compatibilized film waste. Once again, the material compatibilized with PE-g-MA showed a superior performance due to the presence of the polyamide component, which provides a synergic effect that assists the compatibilization reaction with PE-g-MA. Similar effect has also been reported by Araújo et al. ${ }^{[23]}$, where only the blend compatibilized with maleic anhydride showed super-toughness at room temperature.

\section{Conclusions}

The design of experiments guided the construction of PET/PE model-blends, which were used to screen their physico-mechanical behavior. These models were also used to evaluate the recycling potential of multilayer flexible packaging films that are essentially made of PET/PE components.
The compatibilized model-blends showed higher values of elongation at break with the increase of the concentration of the compatibilizers. However, PE-g-MA seems to be more effective for blends with a lower PET/PE ratio (i.e., matrix of PE), while E-GMA presented better properties at higher PET content. The same trend is present when a screening of the elongation at yield was made.

The impact test performed for the model-blends suggests that both compatibilizers have a more pronounced effect when dealing with lower PET/PE ratios. However, the use of higher concentrations of E-GMA did not bring a proportional enhancement of impact strength, due to the possible formation of crosslinking during the compatibilization reaction.

The recycled blends made of compatibilized multilayer film waste presented an acceptable physico-mechanical performance, mainly when medium to high compatibilizers content were used. Among the two additives studied, PE-g-MA seemed to be a better compatibilizer for the scraps. This is attributed to a synergic effect between maleic anhydride groups present in the compatibilizer with amine groups of the nylon- 6 component in the film waste, which undergo a kinetically favorable reaction of compatibilization.

Overall, the use of polymer compatibilizers have shown to be a useful method for recycling the multilayer structure based in immiscible polymers, creating a sustainable solution for an environmental problem. However, despite of presenting good physico-mechanical properties, care must be taken when analyzing the viability of recycling the compatibilized film waste under an economic perspective. The use of higher amounts of compatibilizer (as in the case of 10 or $15 \mathrm{w} \%$ ) is not a common practice among the recycling industry, due to the high costs of the compatibilizers. Nevertheless, under a scientific approach, the recycling of the multilayer films waste was found to be feasible. 


\section{Acknowledgements}

The authors thank Dow Brasil for accepting publishing this paper, Dow Brasil, M\&G Polímeros and Arkema for donation of the raw materials, G.A.U. and S.V.C. also thanks $\mathrm{CNPq}$ for the financial support.

\section{References}

1 Manrich, S., Frattini, G., \& Rosalini, A. C. (2007). Identificação de plásticos: uma ferramenta para reciclagem. São Carlos: EDUFSCar.

2. Coltelli, M. B., Giani, M., Lochiatto, F., Aglietto, M., Savi, S., \& Ciardelli, F. (2004). Postconsumer polyethylene terephthalate (PET)/polyolefin blends through reactive processing. Journal of Material Cycles and Waste Management, 6(1), 13-19. http:// dx.doi.org/10.1007/s10163-003-0100-z.

3. Wagner, J. R., Jr. (2010). Multilayer Flexible Packaging: technology and applications for the food, personal care and over-the-counter pharmaceutical industries. Rochester: Elsevier.

4. Coltelli, M. B., Savi, S., Aglietto, M., \& Ciardelli, F. (2009). A chemical view onto post-consumer poly(Ethylene Terephthalate) valorization through reactive blending with functionalized polyolefins. Polymer Science, Series A, 51(11-12), 1249-1261. http://dx.doi.org/10.1134/S0965545X09110108.

5. Chiu, H. T., \& Hsiao, Y. K. (2006). Compatibilization of poly(ethyleneterephthalate)/polypropylene blends with maleic anhydride grafted polyethylene-octene elastomer. Journal of Polymer Research, 13(2), 153-160. http://dx.doi.org/10.1007/ s10965-005-9020-z.

6. Kalfoglou, N. K., Skafidas, D. S., \& Kallitsis, J. K. (1995). Comparison of compatibilizer effectiveness for PET/ HDPE blends. Polymer, 36(23), 4453-4462. http://dx.doi. org/10.1016/0032-3861(95)96853-Z.

7. Boutevin, B., Lusinchi, J. M., Pietrasanta, Y., \& Robin, J. J. (1996). Improving poly(ethylene terephthalate) high-density polyethylene blends by using graft copolymers. Polymer Engineering and Science, 36(6), 879-884. http://dx.doi. org/10.1002/pen.10475.

8. Lopes, C. M. A., Goncalves, M. D. C., \& Felisberti, M. I. (2007). Blends of poly(ethylene terephthalate) and low density polyethylene containing aluminium: a material obtained from packaging recycling. Journal of Applied Polymer Science, 106(4), 2524-2535. http://dx.doi.org/10.1002/app.26769.

9. Bartoli, F., Bruni, C., Coltelli, M. B., Castelvetro, V., \& Ciardelli, F. (2012). Conversion of post-industrial pet-pe scraps into compatibilized plastic blends for new applications. In 6th International Conference on Times of Polymers (TOP) and Composites (pp. 160-162). Ischia: American Institute of Physics.

10. Utracki, L. A. (2002). Polymer blends handbook. Netherlands: Kluwer Academic Publishers.

11. Barros Neto B., Scarminio, I. S., \& Bruns, R. E. (2010). Como fazer experimentos: pesquisa e desenvolvimento na ciência e na indústria. Porto Alegre: Bookman.

12. Sundararaj, U., \& Macosko, C. W. (1995). Drop breakup and coalescence in polymer blends: the effects of concentration and compatibilization. Macromolecules, 28(8), 2647-2657. http://dx.doi.org/10.1021/ma00112a009.

13. Harrats, C., Thomas, S., \& Groeninckx, G. (2006). Micro and nanostructured multiphase polymer blend systems. United States: CCR Press.

14. Uemura, S., \& Takayanagi, M. (1966). Application of the theory of elasticity and viscosity of two-phase systems to polymer blends. Journal of Applied Polymer Science, 10(1), 113-125. http://dx.doi.org/10.1002/app.1966.070100109.

15. Martuscelli, E. (1984). Influence of composition, crystallization conditions and melt phase-structure on solid morphology, kinetics of crystallization and thermal-behavior of binary polymer polymer blends. Polymer Engineering and Science, 24(8), 563-586. http://dx.doi.org/10.1002/pen.760240809.

16. Macosko, C. W., Jeon, H. K., \& Hoye, T. R. (2005). Reactions at polymer-polymer interfaces for blend compatibilization. Progress in Polymer Science, 30(8-9), 939-947. http://dx.doi. org/10.1016/j.progpolymsci.2005.06.003.

17. Lusinchi, J. M., Boutevin, B., Torres, N., \& Robin, J. J. (2001). In situ compatibilization of HDPE/PET blends. Journal of Applied Polymer Science, 79(5), 874-880. http:/ dx.doi.org/10.1002/1097-4628(20010131)79:5<874::AIDAPP120>3.0.CO;2-B.

18. Carvalho, G. B., \& Souza, J. A. (2009). Compatibilização reativa e tenacificação em blendas poliméricas de PET reciclado com elastômeros olefínicos. In Anais do $10^{\circ}$ Congresso Brasileiro de Polímeros (pp. 1-10). Foz do Iguaçu: Associação Brasileira de Polímeros.

19. Yildirim, E., \& Yurtsever, M. A. (2012). A comparative study on the efficiencies of polyethylene compatibilizers by using theoretical methods. Journal of Polymer Research, 19(2), 1-12. http://dx.doi.org/10.1007/s10965-011-9771-7.

20. Tedesco, A., Krey, P. F., Barbosa, R. V., \& Mauler, R. S. (2002). Effect of the type of nylon chain-end on the compatibilization of PP/PP-GMA/nylon 6 blends. Polymer International, 51(2), 105-110.

21. Becker, D., Porcel, F., Hage, E., Jr., \& Pessan, L. A. (2008). The Influence of the compatibilizer characteristics on the interfacial characteristics and phase morphology of aPA/ SAN blends. Polymer Bulletin, 61(3), 353-362. http://dx.doi. org/10.1007/s00289-008-0956-0.

22. Orr, C. A., Cernohous, J. J., Guegan, P., Hirao, A., Jeon, H. K., \& Macosko, C. W. (2001). Homogeneous reactive coupling of terminally functional polymers. Polymer, 42(19), 8171-8178. http://dx.doi.org/10.1016/S0032-3861(01)00329-9.

23. Araújo, E., Hage, E., Jr., \& Carvalho, A. (2003). Compatibilization of Polyamide 6/ABS Blends using MMA-GMA and MMAMA Reactive Acrylic Copolymers. Part 1. Rheological and Mechanical Properties of Blends. Polímeros: Ciência e Tecnologia, 13(3), 205-211. http://dx.doi.org/10.1590/S010414282003000300011.

Received: Oct. 14, 2014

Revised: Feb. 27, 2015 Accepted: Mar. 06, 2015 